\title{
Nursing values as social practice: a qualitative meta-synthesis
}

\author{
Elma Lourdes Campos Pavone Zoboli
}

Mariana Cabral Schveitzer ${ }^{2}$

\begin{abstract}
Objective: to identify values which structure and guide nursing as social practice. Method: qualitative meta-synthesis. Results: three concepts were identified: The tension between technique, organization and ethics in the nurse's practice; Historical carry-overs of the values which run through nursing practice; Attention to ethics, to reform of the health system, and to the humanization of care. These led to the synthesis of the principal variables 'planning' and 'care', which represent, respectively, guiding values of the technical-operative and ethical-moral elements of the social practice of nursing. Conclusion: these values are articulated through the prism of ordering so as to care well. Their recognition contributed to a better understanding of the process of health care and nursing care.
\end{abstract}

Descriptors: Social Values; Ethics, Nursing; Professional Practice; Social Responsibility.

\footnotetext{
${ }^{1}$ PhD, Associate Professor, Escola de Enfermagem, Universidade de São Paulo, São Paulo, SP, Brazil.

2 Doctoral Student, Escola de Enfermagem, Universidade de São Paulo, São Paulo, SP, Brazil. Scholarship holder from Coordenação de Aperfeiçoamento de Pessoal de Nível Superior (CAPES).
} 


\section{Introduction}

Social practices are activities for meeting people's needs, seen as social beings. They have a profound feeling of humanity, as they take place within the scope of interpersonal relationships and in the search for human survival. They are, for this reason, different from natural behaviors ${ }^{(1)}$. They are part of the cultural and historical process of the intentional interactions between human beings, and between these and the natural world and things.

Social practice is any socially-established coherent and complex form of cooperative human activity involving standards of excellence, obedience to rules and realization of internal goods. These are the zeal of the practitioners to reach excellence, not the individual, but the practice in itself, which benefits all the participants with the credibility, the social recognition and the expansion of the human potentialities. The internal goods are like jewels of each practice, which can be reached only through realization of their standards of excellence $^{(2)}$. For example, the contentment of being able to contribute to improving somebody's health is an internal good of nursing.

Understanding nursing as a social practice means going beyond its technical-operative dimensions resulting from the direct application of biotechnological knowledge and seeing it as one of many of society's practices, with which it shares responsibility for health. Nursing, therefore, is seen as an integral part of the process of the production of health, maintaining a correlation with the social end of work and social institutions ${ }^{(3)}$.

Practice is the action of Man on the things, that is, the application of knowledge in concrete situations with an activity directed toward a specified end. The practice of nursing has an end, human health, and seeks to transform it, intentionally and through planning, through means and instruments ${ }^{(3)}$. Its end product is nursing care for the person at different points of the health-illness process ${ }^{(1)}$.

As a social practice, nursing is a dynamic profession, subject to constant transformations and to the incorporation of reflections and actions on new issues and problems, but always guided by the ethical principle of keeping or restoring dignity to all ambits of life ${ }^{(1)}$. To this end, nurses need to develop a comprehensive and interactive perspective on social and health matters, in consonance with these areas' complexity and the pluralities of contemporary society.
To take account of practice's social purposes and to interlink nursing's technical and ethical elements, it is necessary for the nurse to combine - in the everyday of work - principles and values with technical competency, in an atmosphere of co-responsibilization and receptiveness. This requires of the nurses a human sensitivity which is manifested in interest, respect, attention, comprehension, consideration and affection for the other and for the community. It also entails political engagement in the transformation of what is incompatible with the dignity of the human being, so as to eliminate unnecessary, evitable inequalities, and encourage whatever leads people to live well and with quality.

Commitment is the core of social practices. The guiding values of the practice are within this, as objectimages to be made real, to a greater or lesser extent, in the activities of each practice ${ }^{(4)}$. In nursing, this commitment is to care, and creates the ethical appeal of radical responsibilization in the promotion of the person, respecting and encouraging his or her autonomy, citizenship, dignity and health.

The values are realities, with a constructivist and hermeneutic character, that is, human constructions with a subjective, social, cultural and historical character, which give meaning to things and activities ${ }^{(4)}$. In their constitution and realization they carry objective, subjective and intersubjective elements. In the professional practice, the values constitute axes around which their activities revolve and their excellence spirals. Because they are constructions, the values of a social practice need to be understood from interpretive perspectives of their history, and to be open to the current context and future challenges.

The values may be of two types: 'end values' and 'means values'. The first are those which are valuable in and of themselves and are not 'for something'. The second are instruments 'for', that is, they have value in reference to something different from themselves ${ }^{(5)}$.

This background resulted in the question: which values structure and guide nursing as a social practice? This article aims to discuss the values of the technical and ethical aspects of nursing care as structuring axes of the nurse's social responsibility and ethical-professional commitment in the promotion of health and living conditions which are compatible with human dignity.

\section{Method}

The qualitative meta-synthesis was undertaken through interpretive summary of the data. Qualitative 
meta-synthesis is a scientifically-rigorous research method, which allows one to confront, break down, integrate and transform the results of qualitative primary studies in a process of translation and summary. The abstraction is widened to reinterpret the primary interpretations of the original studies. For this, the results of the primary studies are separated from the context where they were obtained for grouping into new categories in the second, meta-synthesis, study ${ }^{(6)}$.

The objective of the meta-synthesis, in widening the abstraction, is to apply greater use to the results of the different research projects and to facilitate their use in the grounding of health care actions, in formulating policies and future studies, principally where these deal with subjective, non-quantifiable variables. The identification of consensus, the development of hypotheses and the exploration of contradictions between the primary studies makes it possible to theorize and increases the results' reach in the face of generalization, making the qualitative findings closer to use in practice ${ }^{(6-7)}$.

Despite the method used in the primary studies included in the synthesis study, the qualitative meta-synthesis concentrates on the similarities and differences of the language, in the concepts, images and ideas referent to the phenomenon studied. The aim is to widen the interpretive possibilities of the primary results through constructing explanations in narratives or theories ${ }^{(8)}$.

The validity of synthesis research is in the integrative logic of the results of primary studies in a new final product. The integrative synthesis may be made through aggregation or configuration. In the former, the focus is on the thematically-similar findings and through fusion, based in confirmation and repetition, and one arrives at a summary of the set of original studies. In configuration, in addition to the similarities, the contradictions, differences and relationships are indicated, as they treat the results as complementary elements to be integrated, inductively and deductively, in an arrangement illustrating their links and where they fit together. Significant contributions can result from this operation for constructing theories or models, so much so that one of the techniques used in the synthesis of the results is grounded theory ${ }^{(9)}$. In the present research, the decision was made to select configuration.

The research question arose during the undertaking of empirical studies on the interface of bioethics and primary care, which were: a doctoral thesis(10); three financed research projects (National Council for Scientific and Technological Development (CNPq) and the Research Support Foundation of the State of São Paulo (FAPESP)) and four undergraduate courses (Scientific Initiation Scholarship (PIBIC) University of São Paulo (USP), CNPq and FAPESP) ${ }^{(11-14)}$, resulting from a doctorate study and carried out between 2003 and 2008, and a habilitation thesis ${ }^{(15)}$. The undergraduate course research (PIBIC USP) on the good nurse's ethical image $^{(16)}$ also contributed to the questions on the values for nursing's social practice.

In these research projects, resulting from some behaviors and concerns in the discoursive elements analyzed, resulted questions about the values which are most propitious to the consolidation of nursing as social practice. Among others, these behaviors and concerns referred to: link; the nurse's obligation to 'provide answers' to the service users' health, social and family problems; indignation and suffering due to the lack of structure, conditions, companionship in the teams and contribution from management for the care necessary; urgency of organizing the processes of work and individual production, of the teams and of the services to care well, ensuring the universal and equitable access of service users to the Unified Health System (SUS); clear communication to achieve the user's compliance with treatment; concern with the cleanliness and appearance of staff and environments, including the health services and the homes of the families assisted.

The first step in the production of the data, was to re-visit the results of some of the research projects cited $^{(10-12,15-16)}$

The second step, still in the production of data, was the definition of the theory sample (literature), in an intentional way, based in what had been delineated in the analysis of the previous step's empirical sample. The following were included: (1) articles about the professionalization of nursing as proposed by Florence Nightingale, as the subjects were nurses trained under this model(17-21); (2) text books by Ms Nightingale herself, so as to distinguish some of the profession's historical and traditional aspects ${ }^{(22-23)}$; (3) books on the conformation of care in the history of humanity and health, to understand its specificity in nursing(24-25); (4) documental analysis of dissertations and theses, through a systematic review in the collections of the University of São Paulo Digital Library (Biblioteca Digital de Teses e Portal Dedalus) and of the Coordination for Higher Education Staff Development (CAPES).

The purpose, in item (4), was to explore Brazilian productions taking nursing as a social practice in their original reports, so as to delineate values which 
advocate, explicitly or implicitly, for nursing care. It was decided to read the original documents so as to deepen the exploration of the values underlying the works. As the area of the nurses' functioning had been restricted to basic care in the empirical sampling of the first step, with the incorporation of the documental analysis this was widened.

The study did not involve human subjects, as it incorporated the results of primary studies. The latter had been authorized by research ethics committees.

\section{Results}

Based on the analysis of the data, three concepts were developed: Tension between technique, organization and ethics in the nurse's practice; Historical carry-overs of the values which run through the practice of nursing; Attention to ethics, to reform of the health system, and to humanization of care. Two principal variables were derived from these: 'planning' and 'care' (Figure 1).

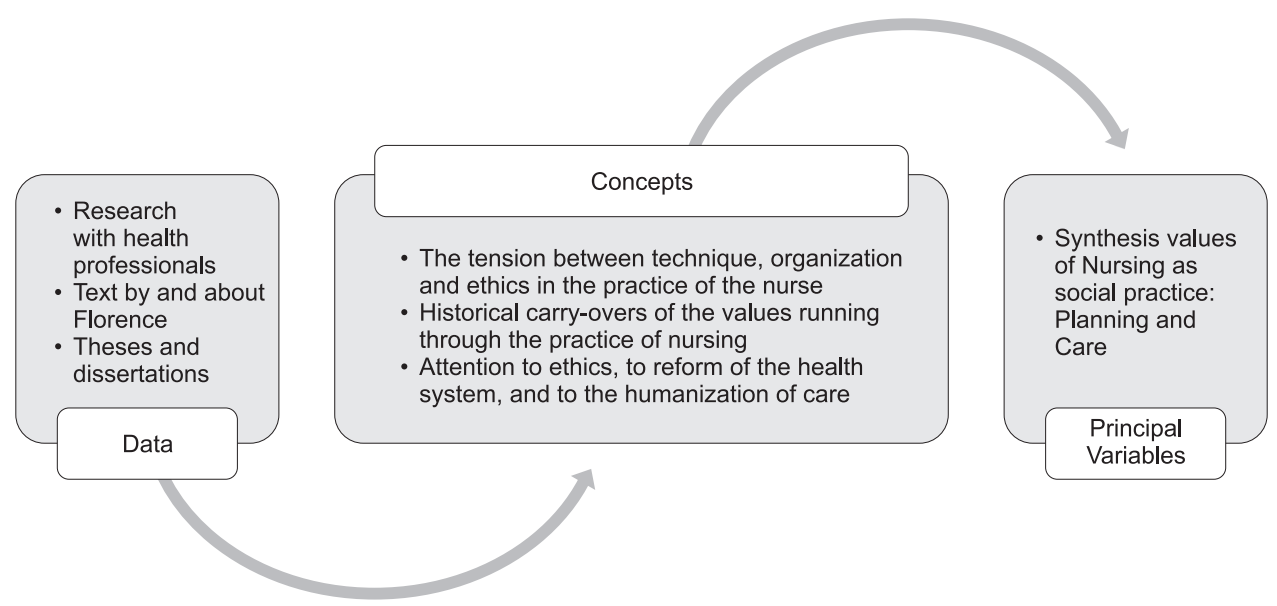

Figure 1 - Planning and care as summary values of Nursing as social practice

\section{The tension between technique, organization and ethics in the practice of the nurse}

In the first step, the analyses relative to the results of the studies on the interface of bioethics and basic care $^{(10,12,15)}$ outlined, for the nurses, a double area of their professional responsibility: the individual care for service users or their families, and the maintenance of the organization of the services for caring well.

There were institutional successes in the family health teams for organizing the process of work and production, with the aim of attending well those with the greatest need: "we have a strategy, the work proposal, people with hypertension and diabetes do not need to book appointments, they are all classified and those from Group C see the doctor every six months with all the tests, if a person is diabetic, he sees the doctor every three months" (Nurse 13)(10).

The nurses reported that "there's a time for everything" (N2), also in the organization of the health center, as "you have to explain to them that it's not when they are available that things happen, but rather when you have the conditions to do it, and there's a routine to follow" (E14), "unless immediate care is required, you have to impose some limits" (N13) ${ }^{(10)}$.

The service users were recognized as having rights and duties: "we have our duties as health professionals, and the patient has his" (N13)(10). The nurses felt responsible for the service user, as he "will be ours forever, we can't just abandon this patient" $(\mathrm{N} 10)^{(10)}$. There were nurses who understood this responsibility as an imposition of the health system, because "disconnecting from the patient is difficult in the Family Health Program" $(\mathrm{N} 10)^{(10)}$; "because they don't choose the health professionals, we can't choose patients either" (N3)(10).

The flaws in the organization of the services, in the process of production and in the physical structure of the health centers represented obstacles to putting into effect ethical benchmarks which were important for nursing care. For example, privacy was compromised by shortcomings in the physical plant: "you can hear (what the patient's complaint is) out in reception" (N1) ${ }^{(10)}$.

The hierarchy in the delineation of the areas and the specialities of the health professionals and the team 
was included in the organization. Usually, the nurse respected these limits, unless they impeded good care for the service user, in which case, even though suffering morally, the nurse would contravene the organization so as to care well. For example, in caring for a patient with a urinary tract infection and syphilis, which the doctor had attended without solving these problems noted in the patient health records, the nurse waited for the doctor to go away before conversing with another professional to obtain the treatment she judged necessary. In the report of this case, one can read that the nurse considered her action unethical, but justified it in view of the resolution of the patient's health problem ${ }^{(11-12)}$

Obedience to orders from superiors, when it impedes good nursing care, creates conflicts and suffering. As, for example, in the case of the anguish of a nurse who received orders from management not to remain at work after the end of her working hours and was therefore obliged to leave the body of a patient who died in the center under the responsibility of the porter until the arrival of the Coroner's Office(11-12).

In relation to research on the ethical image of the nurse(16), the analysis of the first step outlined hierarchical elements and organization, which included: carrying out duties; respect for rules and conducts; meeting standards of cleanliness and clothing; a harmonious balance in the environment; regulation of individual behaviors; obedience; subservience; subordination of the nurse to the doctors' orders; and authority over the patient to make him comply with the medical prescriptions.

Also outlined was the value of the proactive nurse, politically engaged and who integrates the human and technical elements of the care so as to benefit the patient's protagonism and autonomy. Further, the image of the ethical nurse included preparation and availability to welcome the other as a person, performing with skill, competency, excellence and autonomy in the professional functions ${ }^{(16)}$.

\section{Historical carry-overs of the values which run through nursing practice}

The analysis of the second step, items (1), (2) and (3), substantiated the comprehension of the 'organization' and 'care', based on nursing's historical carry-overs.

The readings made it clear to the researchers that there were periods in which the care did not belong to specified trades or professions, but had to do with the practices of who helped the other to ensure what was necessary to stay alive. With the world's cultural, technological, social, economical, political and geographical transformations, the care practices widened and opened out into various tasks and activities, argued over by those practising trades and professions ${ }^{(24)}$.

In the texts, the profession was seen as a body of persons who managed to get a title and created a statute through training which was specific to exercising a specific activity. The members of this body recognize each other through their common training or by the nature of the activity itself(24).

Through the analysis, however, it was found that the professions are, also, jobs which people do to support themselves and meet their own needs and those of society. The professionals are the work force, even though they differentiate themselves from other workers by the extent of the control they have over their own work. They are "professional workers", as they regulate their work activities through professionalism ${ }^{(10)}$.

People's insertion in specific social classes was determined by profession, with a place marked out in the hierarchy of the powers which regulate society. On the other hand, the trades were provisions of service to the community and had no societal regulatory function. Its practitioners were, simply, suppliers of services who were indispensable to survival(24).

With the capitalist mode of production, profession and trade became closer. The professions passed to 'provide services' and use instruments developed by the trades. So as to maintain their regulatory power, the professions increasingly turned to scientific knowledge ${ }^{(24)}$.

Regardless of the myriad historical aspects which surround the constitution of nursing as a 'modern profession', these results clarified that it occurred in the process of the approximation between trade and profession. With this, its technical-operative components (which incorporated trades which provided services) and ethical-moral components (which encompassed professions which regulated the social order to maintain life) were determined. These components were associated so strongly in the configuration of modern nursing that, until today, an urgency persists for amalgamating technique and ethics in the social practice of nursing(24).

In the Nightingalian proposal for organization of nursing, the analyses of the texts showed that curing and delaying death motivated the care, determining its expression in the organization of the environment, in the planning, in the steps taken for sanitation and cleaning 
of hospitals and housing. For Florence Nightingale, nurses had to remain equally interested in the patient as a person, in the organization and in their improvement, personally, intellectually and in terms of their skills. It is a tense meeting of care and organization.

The propensity for order, a personal characteristic of Ms. Nightingale's which ended up imprinted on nursing, marked the profession's tendency for systemic approaches to life. Florence had astuteness for understanding the interdependency of things, bringing order to complexity. Faced with problems, she identified and prioritized the essential elements, creating between them relationships which facilitated their cohesion and synergy. For her, as the analyses showed the authors, order extracted the 'complications' from the complexity and thus she recommended that each one should order their internal and external worlds(3).

\section{Attention to ethics, to reform of the health system, and to the humanization of care}

The results of the documental analysis of theses and dissertations, item (4) of the second step, showed the following as valuable for the social practice of nursing: Attention to ethical basics (observance of the code of ethics, attention to ethical questions and use of bioethics); Engagement in the consolidation of the SUS (engagement for the effectiveness of the SUS and transformation of the work process); Humanization of the health care (humanization of health and knowledge of the human being).

The control, the guidance, the management and the administration appeared, in the analysis, as characteristic elements of the nurse's work process, distinguishing the nurse from the other professionals in the health team. Nursing, as a social practice, represents concrete possibilities for transforming society and the health system, as the reorganization of the services and processes of the production of health is essential in the humanization of nursing care.

\section{The synthesis values: planning and care}

The principal variables 'planning' and 'care' are indicated as synthesis values or end values, for nursing as a social practice.

The technical-operative component supports the 'planning' value. This is a synthesis value, an end value, which aggregates values through: order, planning, preparation, coordination, tidiness, distribution, allocation, organization, classification, cataloguing, grouping, conditioning, regulation, alignment, restoration, taxonomy, syntax, analysis, systematization, installation or re-establishment of order, normalization, regularization, methodization, registration, uniformization, orientation, harmony, harmonization, protocolization, formalization, hierarchization, hierarchy, and direction.

The ethical-moral component supports the synthesis value 'care', another value which aggregates values, through: helpfulness, zeal, commitment, attention, effort, interest, conscience, consciousness raising, diligence, attention to detail, refinement, tenderness, meticulousness, vigilance, correction, good disposition, exactitude, thoroughness, attentiveness, seriousness, observation, doing rounds, knowing the job, being alert, being prepared for eventualities, proportionality, feeling responsible for, perseverance, vivacity, motivation, energy, initiative, entrepreneurship, enthusiasm, dedication, impetuosity, capacity to overcome obstacles so as to arrive at the desired end, agility, dexterity, punctuality, enthusiasm, dynamic spirit, assiduity, constancy, and indefatigability.

The value 'care' may be considered an end value par excellence, as the planning is to care.

\section{Discussion}

This section discusses the end values of nursing as a social practice, which resulted from the meta-synthesis: planning and care. Through constant comparison, the meta-synthesis, by configuration, made it possible to raise some interpretive and explanatory hypotheses for the structuring of the social practice of nursing, which are grouped, in the discussion, around the two synthesis values.

Nursing is driven by 'love for life', a 'biophilia', which is expressed in the doctrine of promoting or developing that which lets people or groups live. It is realized in the provision of service in a professional job, which nurses make possible to society with their social practice. This practice has as its product 'nursing care', and has as its motto meeting people's health needs, individually or collectively. This includes transformation of the environment, understood as the determinants and constraints of people's and groups' health, and the improvement of the systems, services, and processes of work and of health production, as an essential element for caring well.

The historical carry-over of nursing care, as a professional provision of a social category or class, 
shows that these develop around two axes: ensuring the continuity of life, and delaying death or driving away what is bad or dangerous. Both are articulated for the improvement of humanity through good conditions of life and health. Within nursing, the articulation of these two axes operates the conjugation of the ethical-moral and technical-operative components.

Caring for life was one of the first arts developed by humans, constituting a heritage of knowledge, which finally made up the basics of care practices. In the professionalization of care, the hegemony of the capitalist mode of production was determinant, with the social division of work.

The modern phase of the professionalization of nursing occurred in the middle of the approximation of professions and trades in the world of work. Florence Nightingale's proposal desired integrality for nursing care, which included the promotion of life and the driving away of whatever threatened or impaired it, with nurses well prepared in heart and mind.

Planning and care are articulated in nursing's social practice, through the prism of ordering so as to care and thus promote people's potential and dignity. It is an attempt to rescue the original initial locus of care, as a motivational doctrine of a fruitful and supportive social practice, with articulation of technical and moral excellences through personal discipline and discipline of the environment, including the nurses' work process and the health services and systems.

Brazilian nursing, as this study's results demonstrate, seeks to synthesize and carry out in its practice, social values of care for people and the organization. That is, the care, as a moral imperative and the planning, as zeal for order, have the purpose of viabilizing practical wisdom, of prudence and discernment, in the complexity of health and society: a wisdom, which is the knowledge of how to use the knowledge, the knowing of nursing, so as to care well for everything and everyone.

To care well, one needs integral health care, which in its turn depends on the nurse's ability to understand the social context, to identify people's health needs and expectations, to strengthen individuals' qualities, to promote interaction between service users, the team and the community(26).

Nursing's social practice can be the motor for a continuous (re-)construction of its knowing and doing, as it raises the awareness of nurses in relation to the complexity of the reality in which they work and in relation to the return to the essence of care in this practice(27) $^{(27}$
For this, the nurse's technical-political competencies are also important, which are expressed in the responsibility and in the commitment with the service users, and in the articulation and integration of the health services for resolutive attendance(26).

The link between feelings and values, fruit of the determinant social hierarchization, forges the sharing of the same esthetic of care. In the history of nursing, the social, cultural and esthetic factors were fundamental to optimize its professional and pre-professional values. The esthetic standards, understood as something which regulates the production of knowledge, occur in the organization of care, based on socializing structures of feelings such as motherhood, piety, altruism, empiricism, technicism, professionalism, scientificism and humanism ${ }^{(28)}$. The present research points to the articulation of the planning and care in nursing's social practice, explaining one of the routes through which the esthetic standards and the socializing structures are arranged dialectically in the professionalization of nursing.

The scientific production on leadership in nursing evidences it as an organizational tool for the articulation of communication, interpersonal relationships, planning, commitment to success and the resolution of conflicts, such that the caring work of nursing may be undertaken safely ${ }^{(29)}$. These evidences point to the application of the synthesis values of planning and care in the management of nursing and of the care.

\section{Final Considerations}

To recognize the structuring and guiding values of nursing as a social practice contributes to the understanding of the foundation and of the recurrence of some attitudes and behaviors of nurses. To understand the values of planning and care as indicators of nursing as a social practice can contribute to recognition of what supports or weakens the work of the nurse in the process of attention and care to health.

In understanding care as an end value of nursing, it is possible to confer a new tone on the work of the nurse, because the concretization of this value in the everyday activates the ordered and organized integration of the technical-operative and ethical-moral elements which conform this social practice.

What gives meaning to nursing as a social practice is the planning for good care; order and organization are crucial in caring well. Thus, maintaining networks, services, teams and health production processes 
organized, that is, 'in order', seems to be important to reduce the nurses' strain, especially in primary care, the preferred setting of the primary studies which were synthesized.

Being founded in a social practice, the values of planning and caring - bearing in mind that this practice is that of nursing, which has in its historical carry-over the protection of life - raise new questions about what the lexical order between these two synthesis values should be.

\section{References}

1. Trezza MCAF, Santos RM, Leite JL. Enfermagem como prática social: um exercício de reflexão. Rev. Bras Enferm. 2008; 61(6):904-8.

2. Macintyre A. After virtue. 2nd ed. Notre Dame: University of Notre Dame Press; 1984. 304p.

3. Chiesa AM, Bertolozzi MR, Fonseca RMGS. A Enfermagem no cenário atual: ainda há a possibilidade de opção para responder às demandas da coletividade? O Mundo da Saúde. 2000; 24:67-71.

4. Gracia D. La cuestión del Valor. Discurso de recepción del Academico. [internet]. Real Academia de Ciencias Morales y Políticas; 2010. [acesso em: 10 abril 2012]. Disponível em: http://www.racmyp.es/docs/discursos/ D81.pdf

5. Moore GE. Principia Ethica. Cambridge: Cambridge University Press; 1993. 313 p.

6. Sandelowski M, Trimble F, Woodard EK, Barroso J. From synthesis to script: Transforming qualitative research findings for use in practice. Qual Health Res, 2006; 16(10):1350-70.

7. Zimmer L. Qualitative meta-syntesis: a question of dialoguing with texts. JAN. 2006; 52(5):546-53

8. Sandelowski M, Barroso J. Classifying the findings in qualitative studies. Qual Health Res. 2003; 13(7):905-23.

9. Sandelowski M, Docherty S, Emden C. Qualitative Metasynthesis: issues and techniques. Research in Nursing \& Health. 1997; 20:365-71

10. Zoboli ELCP. Bioética e atenção básica: um estudo de ética descritiva com enfermeiros e médicos do Programa Saúde da Família [tese de doutorado]. São Paulo (SP): Faculdade de Saúde Pública da Universidade de São Paulo; 2003. 253p.

11. Lima AC, Morales DA, Zoboli ELCP, Sartório NA. Problemas éticos na atenção básica: a visão de enfermeiros e médicos. Cogitare Enferm. 2009;14(2):294-303.
12. Zoboli ELCP. Relación clínica y problemas éticos en atención primaria, São Paulo, Brasil. Atención Primaria. 2010;42(8):406-14.

13. Zoboli ELCP. Nurses and primary care service users: bioethics contribution to modify this professional relation. Acta Paulista Enferm. 2007;20(3):316-20.

14. Silva LT, Zoboli ELCP, Borges ALV. Bioética e atenção básica: um estudo exploratório dos problemas éticos vividos por enfermeiros e médicos no PSF. Cogitare Enferm. 2006;11(2):133-42.

15. Zoboli ELCP. Deliberação: leque de possibilidades para compreender os conflitos de valores na prática clínica da atenção básica. [tese de livre docência]. São Paulo (SP): Escola de Enfermagem da Universidade de São Paulo; 2010. 348p.

16. Sartório NA, Zoboli ELCP. Images of a 'good nurse' presented by a teaching staff. Nursing ethics. 2010;17(6):687-94.

17. Wagner DJ, Whaite B. An exploration of the nature of caring relationships in the writings of Florence Nightingale. J Holist Nurs. 2010;28(4):225-34.

18. Dossey BM. Florence Nightingale: Her personality type. J Holist Nurs. 2010;28(1):57-67.

19. Hegge M. The empty carriage: lessons in leadership from Florence Nightingale. Nurs Sci Q. 2011;24(1):21-25 20. McDonald L. Florence Nightingale on public health care. Waterloo: Wilfried Laurier University Press; 2004. $700 p$.

21. McDonald L. Florence Nightingale's suggestions for thought. Waterloo: Wilfried Laurier University Press; 2008. 794p.

22. Skretkowicz V. Florence Nightingale's Notes on nursing: what it is and what it is not \& Notes on Nursing for Labouring Classes: commemorative edition with historical commentary. New York: Springer Publishing; 2010. 96p.

23. Nightingale F. Florence Nightingale to her nurses. Stillwell: Digireads; 2007. 80p.

24. Collière MF. Promover a vida: da prática das mulheres de virtude aos cuidados de enfermagem. $5^{\text {a }}$ ed. Lisboa: Lidel; 1999. 388 p.

25. Colliere MF. Cuidar a primeira arte da vida. $2^{a}$ ed. Loures: Lusociência; 2003. 448p.

26. Backes DS, Erdmann AL, Büscher A. Demonstrating nursing care as a social practice. Rev. Latino-Am. Enfermagem. 2009;17(6):988-994.

27. Prochnow AG, Leite JL, Erdmann AL. Geertz' interpretive theory and care management: visualizing nurses' social practice. Rev. Latino-Am. Enfermagem 2005;13(4):583-90. 
28. Siles Gonzales J, Solano Ruiz, MC. Cultural history and aesthetics of nursing care. Rev. Latino-Am. Enfermagem 2011;19(5):1096-105.

29. Lanzoni GMM, Meirelles BHS. Leadership of the nurse: an integrative literature review. Rev. Latino-Am. Enfermagem. 2011;19(3):651-8 